\title{
LCA of conventional and alternative vehicles using a "data range-based modeling system"
}

\author{
F. Boureima ${ }^{1}$, N. Sergeant ${ }^{1}$, V. Wynen ${ }^{1}$, H. Rombaut ${ }^{1}$, J. Matheys ${ }^{1}$, \\ J. Van Mierlo ${ }^{1}$, M. De Vos ${ }^{2}$ \& B. De Caevel ${ }^{2}$ \\ ${ }^{1}$ Vrije Universiteit Brussel, \\ Department of Electrotechnical Engineering and Energy Technology, \\ MOBI research group, Brussels, Belgium \\ ${ }^{2}$ RDC-Environment, Brussels, Belgium
}

\begin{abstract}
Nowadays, public authorities are faced with a conflicting situation in which the urgent necessity is to decrease greenhouse gas emissions combined with a steady increase of road traffic. To be able to take the most appropriate and efficient policy measures, the decision makers need to be provided with relevant and complete life cycle environmental impact data for each vehicle technology. Besides the vehicles' environmental life cycle data, the environmental impact of every step of fuels' life cycle must be assessed and provided as well. To achieve that purpose, a special Life Cycle Assessment (LCA) tool allowing the assessment of different vehicle types with different lifetime driven distances in one single model is being developed. A special modeling system (RangeLCA), using a range of values instead of averaged ones, will allow the potential variability of the data to be taken into account. The distribution of the main parameters of the model as well as the influence of their variability on each other will be taken into account thanks to a specific statistical tool integrated in the modeling system. The relevance of the choice of the parameters and the sensitivity of the LCA results to those parameters are checked on a regular basis throughout the modeling process. Temporary LCA results of the Volkswagen Touareg and the Volkswagen Golf as well as a sensitivity analysis of different parameters will be discussed
\end{abstract}

Keywords: environment, alternative fuels, emissions, passenger car, modeling per range. 


\section{Introduction}

Environmental issues related to transport have encouraged the implementation of ecological policies coupled with the related regulations. Choosing one of the closely related policies is the most difficult decision making task. LCA is a decision support tool that allows quantifying and comparing the potential overall environmental impact of a product and/or a service and the resulting environmental effect of a decision. Keeping in view the complexity of the system to be modeled, the standard LCA methodology is being combined with statistical tools in order to improve the reliability of results. The main advantage of this modeling system is to rely on the diversity of all the individual cases instead of average cases, for better clarity of results.

In this paper, the range-based modeling system as well as well its added value in comparison with a classic LCA will be discussed. In addition, this methodology will be used to perform a comparative LCA of the Volkswagen Golf 1.4 and the Volkswagen Touareg 5.0 TDI V10 FAP. Due to insufficient data the results of this study will not include the end-of-life phase but it will for our next task.

Afterwards, the following results will be discussed:

$>$ Greenhouse effect per life cycle phase and their contribution to the life cycle greenhouse effect

$>$ Consumption of non renewable resources per life cycle phase and their contribution to the total life cycle non-renewable resources' consumption

$>$ Comparison of the life cycle environmental impact of the two vehicles (greenhouse effect and non-renewable energy consumption)

Finally, the influence of urban and extra-urban driving on the LCA results will be assessed through a sensitivity analysis.

\section{Methodology}

LCA studies the environmental aspects and potential impacts of a product/service from 'cradle-to-grave' i.e. from raw material acquisitionprocessing-production-the end use until disposal (ISO [1]).

The range-based modeling system possesses some innovative attributes that allow improvement of the reliability of the results. From a statistical viewpoint, this approach employs the use of random variables instead of average values (De Vos and De Caevel [2]). Compared to a classic LCA; it allows assessment of all the possible cases instead of one single case (figure 1). The random values are modeled with parameters that include all the values between the two known extreme values by giving an occurrence probability to each data. According to the situation to be modeled, different types of distribution functions can be chosen. For example a triangular distribution will be chosen when all the values have the same appearance probability and $100 \%$ of them are included in the range. On the other hand, a log-normal distribution function will be used when a 
small part of the values could sometimes be higher or lower than the two extreme values.

One of the main assets of the range-based modeling system is the possibility of expressing a link between two life cycle steps by the prior links in such a way that each variation or change in the previous steps will be automatically taken into account and all different situations will be included in one single model. Thus the sensitivity analysis of all the parameters will be automatically incorporated.
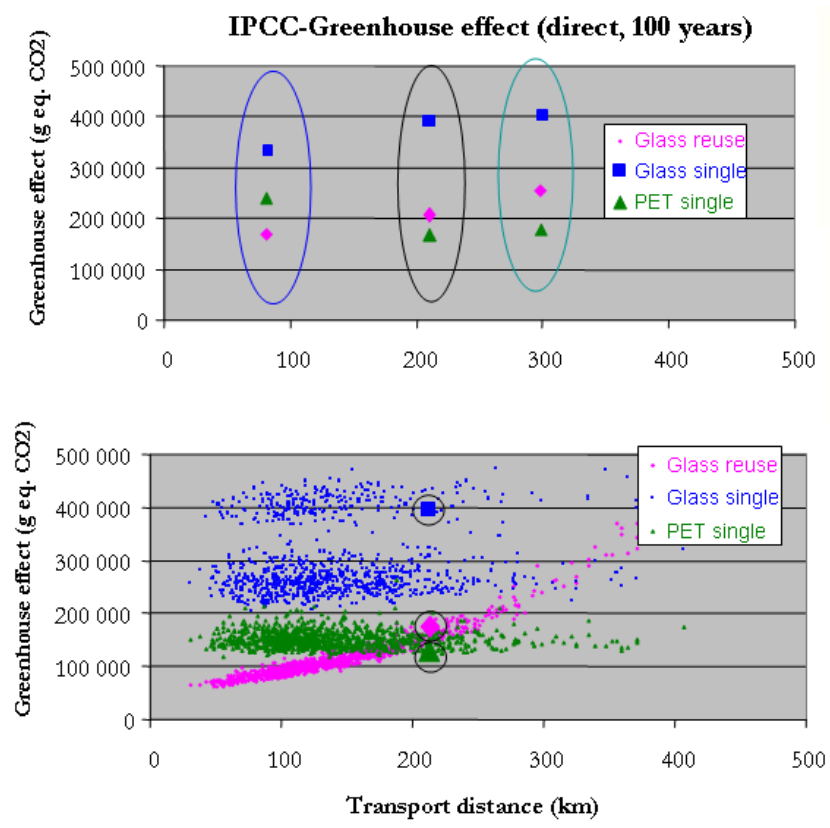

Figure 1: $\quad$ Classic LCA vs. range-based LCA (De Vos and De Caevel [3]).

\section{1 "Discernability" of the systems}

The range-based modeling system allows two systems with simultaneously varying parameters to be compared. In fact, while comparing two different systems within an LCA, two types of variations could happen:

$>$ Variation of the results due to the variation of the parameters that are common to the two systems

$>$ Variation of the results due to the variation of parameters that are specific to one given system.

Thus, to achieve a real comparison of the two systems one should identify and assess the variability of system specific parameters that allow the specificities of each system to be distinguished. Furthermore, this will allow situation specific evaluation of the system for eco-friendliness. 


\subsection{Assumptions}

The LCA model used in this study is not specific to a single car. It includes all the passenger cars of the Belgian fleet. The conventional cars as well as the alternative cars have been classified within different category according to their weight, their length and the Belgian market specifications. The defined categories are City car, Supermini, Small family car, Family car, Small monovolume, Monovolume, Exclusive car, Sport car and Sport utility car. For each category, petrol, bio-ethanol, diesel, bio-diesel, CNG, LPG, hybrid and electric versions are considered.

Thanks to this classification system, all the different types of vehicle technology will be compared within one category. The different categories can also be compared to each other.

To solve the frequent lack of data problem and to avoid modeling the life cycle stages that are common to all the considered vehicles several times, a theoretical car has been modeled. The model of this car will include the raw materials, the manufacturing processes and energy consumption (see table 1) and transport by rail and truck.

Table 1: Manufacturing data of the theoretical vehicle (Spielman et al. [5]).

\begin{tabular}{|l|c|c|}
\hline \multicolumn{1}{|c|}{ Raw materials } & $\begin{array}{c}\text { Uncertainty } \\
\text { (Standard deviation 95\%) }\end{array}$ & $\begin{array}{c}\text { Amount } \\
\text { (kg) }\end{array}$ \\
\hline Steel low alloyed & 1.20 & 99 \\
\hline Aluminum & 1.24 & 51.8 \\
\hline Polyvinylchloride & 1.24 & 16 \\
\hline Zinc & 1.24 & 5.89 \\
\hline Chromium & 1.24 & 2.4 \\
\hline Nickel & 1.24 & 1.4 \\
\hline Palladium & 1.24 & $3.00 \mathrm{E}-4$ \\
\hline Platinum & 1.24 & $1.6 \mathrm{E}-3$ \\
\hline Sulfuric acid & 1.24 & $8 \mathrm{E}-1$ \\
\hline Reinforcing steel & 1.20 & 891 \\
\hline Alkyd paint & 1.24 & 4.16 \\
\hline Polyethylene & 1.24 & 102 \\
\hline Synthetic rubber & 1.24 & 44.1 \\
\hline Flat glass & 1.24 & 30.1 \\
\hline Copper & 1.24 & 10.1 \\
\hline Polypropylene & 1.24 & 49 \\
\hline Manufacturing processes & & 10.1 \\
\hline Copper wire drawing & 1.20 & 541 \\
\hline Steel sheet rolling & 1.20 & 203 \\
\hline Steel section bar rolling & 1.20 & 2140 \\
\hline Electricity & 1.24 & 63 \\
\hline Light fuel oil & 1.24 & 2220 \\
\hline Heat, natural gas & 1.24 & \\
\hline Tap water & 1.24 & 3220 \\
\hline & & \\
\hline
\end{tabular}


This theoretical car will be used as a parameter to model the manufacturing and transport phases for all the vehicle categories according to the following equation:

where

$$
\text { Vehicle }_{\text {cat }}=\frac{\left[w_{\min }, w_{\max }\right]}{w_{\text {theoritical }}} * \text { theroritical }
$$

Vehicle $_{\text {cat }}$ : Manufacturing and transport within a category

$w_{\min }$ : Minimum vehicle weight per category

$w_{\max }:$ Maximum vehicle weight per category

$w_{\text {theoritical }}:$ Weight of the theoretical car

theoritical : Theoretical car

A range of life time driven distance is defined in a Belgian context as a normal distribution function with a standard deviation of 70074.52 and a geometric mean of 230500 (FEBELAUTO [4]), which will be the comparison basis (Functional unit) of all the vehicles (see figure 2). Thereby, The life time driven distance of the vehicles will range from approximately $50000 \mathrm{~km}$ to $400000 \mathrm{~km}$ (see figure 2). This will allow assessing the relative contribution of the production phase to the overall environmental impact regarding the use phase.

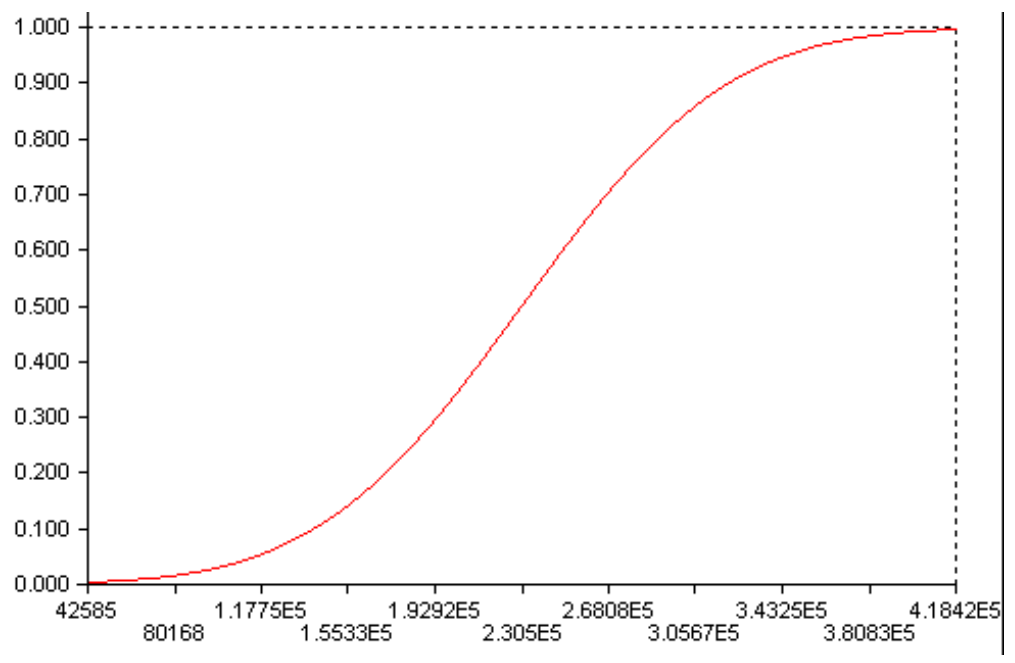

Figure 2: Distribution function of the lifetime driven distance.

To model the use phase, two vehicles from two different categories were chosen to illustrate the interesting features of the range-based modeling system. However, it is important to keep in mind that the system can assess ranges of vehicle. This step has been modeled with a conditional distribution function in 
order to split up the driving conditions into urban driving and extra-urban driving. The conditional distribution insures that the two situations will never happen at the same time and allow attributing an appearance probability (see table 2) to each of these situations in such away that the sum of all the appearance probabilities will be one. In the case of a vehicle category instead of one single vehicle, the fuel consumptions will be expressed in range of values.

Table 2: $\quad$ Urban driving and extra urban driving $[6,7]$.

\begin{tabular}{|l|l|c|c|}
\hline \multicolumn{2}{|c|}{} & $\begin{array}{l}\text { Fuel consumption } \\
(1 / 100 \mathrm{~km})\end{array}$ & $\begin{array}{l}\text { Occurrence } \\
\text { probability }\end{array}$ \\
\hline \multirow{2}{*}{$\begin{array}{l}\text { Volkswagen Golf 1.4 } \\
\text { (Petrol) }\end{array}$} & Urban & 9.4 & 0.25 \\
\cline { 2 - 4 } & Extra-urban & 5.5 & 0.75 \\
\hline $\begin{array}{l}\text { Volkswagen Touareg 5.0 TDI } \\
\text { V10 FAP (Diesel) }\end{array}$ & Urban & 17.9 & 0.25 \\
\cline { 2 - 4 } & Extra-Urban & 9.8 & 0.75 \\
\hline
\end{tabular}

\subsection{The impact calculation}

Two impact categories have been evaluated in this study. The first one is the Greenhouse effect according to the calculation method defined by the Intergovernmental Panel on Climate Change (IPCC, 1998). It allows calculating the greenhouse effect of a product in 100 years in term of kilogram of CO2quivalent by summing-up the global warming potential of all the greenhouse gases emitted by the product. The second considered impact category is the nonrenewable energy consumption defined in 1996 by BUWAL (1996), which is the Swiss agency for the Environment, Forest and Landscape. It is expressed in megajoule (MJ).

Table 3: $\quad$ Life cycle greenhouse effect.

\begin{tabular}{|l|c|c|c|c|}
\hline & \multicolumn{2}{|c|}{ Volkswagen Golf 1.4 } & \multicolumn{2}{c|}{$\begin{array}{c}\text { Volkswagen Touareg 5.0 TDI } \\
\text { V10 FAP }\end{array}$} \\
\hline & g CO2-equivalent & $\%$ & g CO2-equivalent & $\%$ \\
\hline Raw Materials & 2500000 & 4.9 & 3610500 & 3.7 \\
\hline Manufacturing & 1600000 & 3.1 & 2308000 & 2.4 \\
\hline Transport & 36000 & 0.1 & 53100 & 0.1 \\
\hline Use phase WTT & 8650000 & 17 & 10354200 & 11 \\
\hline Use phase TTW & 38500000 & 75 & 80400000 & 83 \\
\hline Total & 51286000 & 100 & 96725000 & 100.0 \\
\hline
\end{tabular}

\section{Results}

In all the environmental assessments of vehicles, the use phase is responsible for the main part of the impacts. The results in the tables 3 and 4 show that for the two considered impact categories the use phase is accounting for more than $88 \%$. To have a clear view of the causes of the impact related to the use phase, it has been split-up into two sub phases:

- the Well-to-Tank (WTT) step which includes all the stages of the fuel production from the feedstock production to the filling station 
- $\quad$ and the Tank-to-Wheel (TTW) step, which corresponds to the use of the fuel in the vehicle.

We observed that for both the two vehicles, the TTW is responsible of more than $75 \%$ of the greenhouse gas emissions. The environmental life cycle impact of the Volkswagen Touareg is $89 \%$ higher than the one of the Volkswagen Golf in term of greenhouse effect and 55\% higher in term of non-renewable energy consumption. In spite of the these big differences between the life cycle impacts of the two vehicles, the contribution of the different life cycle phases to their renewable energy consumption is more or less the same. However the contribution of the WTT step to the life cycle greenhouse effect of the Volkswagen Golf is almost 7\% higher compared to the Volkswagen Touareg. This difference can be explained by the fact that the production of petrol emits more greenhouse gases than the production of diesel.

Table 4: $\quad$ Life cycle non-renewable energy consumption.

\begin{tabular}{|l|c|c|c|c|}
\hline & \multicolumn{2}{|c|}{ Volkswagen Golf 1.4 } & \multicolumn{2}{c|}{$\begin{array}{r}\text { Volkswagen Touareg } \\
5.0 \text { TDI V10 FAP }\end{array}$} \\
\hline & MJ & $\%$ & MJ & $\%$ \\
\hline Raw Materials & 55280 & 6.9 & 81120 & 6.6 \\
\hline Manufacturing & 34400 & 4.3 & 50500 & 4.1 \\
\hline Transport & 620 & 0.1 & 910 & 0.1 \\
\hline Use phase WTT + TTW & 710000 & 88.7 & 1106000 & 89.3 \\
\hline Total & 800400 & 100 & 1238430 & 100 \\
\hline
\end{tabular}

\subsection{Sensitivity analysis}

A sensitivity analysis has been performed to assess the relevance of splitting-up the driving conditions into urban driving and extra-urban driving on the one hand and the contribution of the production phase to the life cycle environmental impact regarding the use phase on the other hand. The sensitivity analysis is performed through a serial of 1000 iterations in which a given impact is calculated within a given range e.g. the consumption of non-renewable energy in urban and extra-urban conditions is calculated for 1000 different values included in the range of driven distances (see figure 3 ). The shorter the lifetime driven distance is, the higher will be the contribution of the production phase (each dot in the figures 3 and 4 represent a produced vehicle). Therefore, vehicles with short lifetime driven distance should be produced more than once to fulfill the service provided in the functional unit e.g. a vehicle with a lifetime driven distance of $115000 \mathrm{~km}$ has to be produced two times to provide the same service. In the case of two or several product systems having common parameters, the sensitivity analysis will allow their comparing on the basis of the non-common parameters (see figure 4). For short driven distances, the contribution of the production phase is the same for the two vehicles when the driven distance varies the same way for them (figure 4). The dispersion of the points corresponds to the range of weight per vehicle category. 


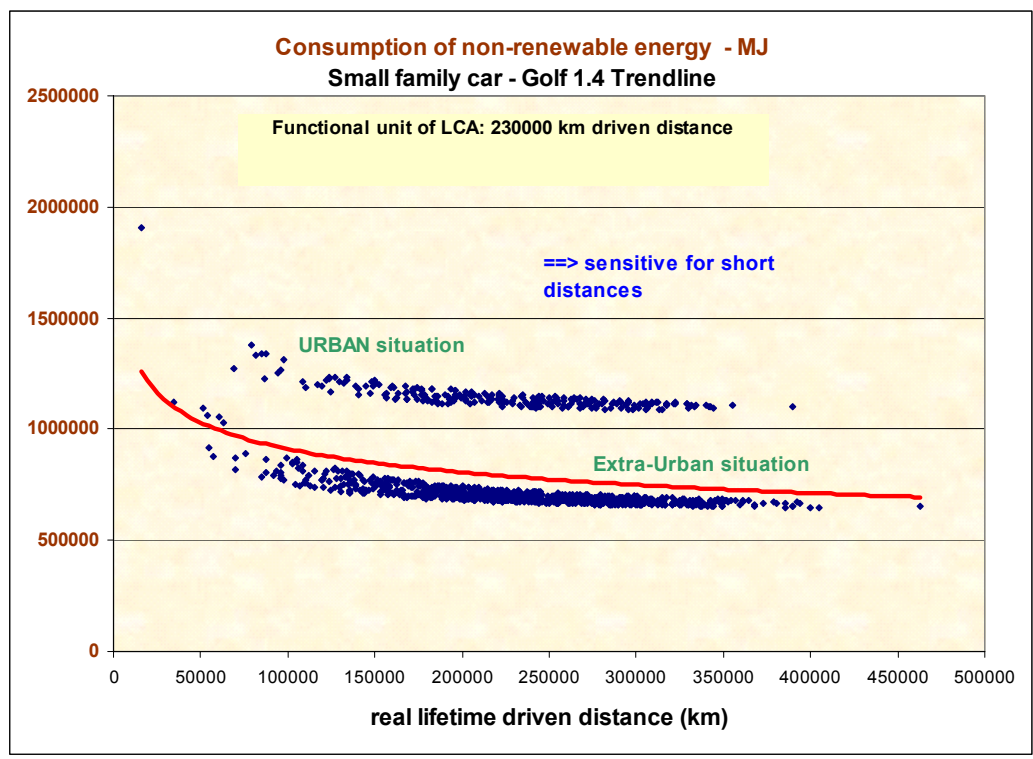

Figure 3: Influence of urban and extra-urban situations on the consumption of non-renewable energy.

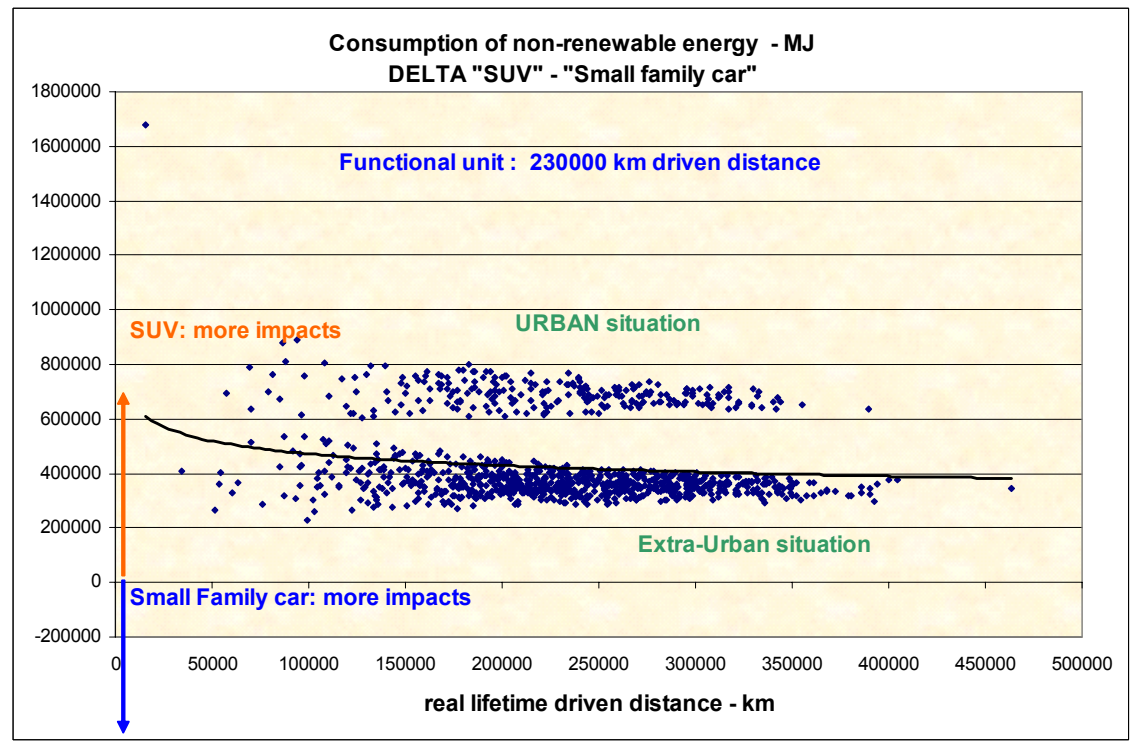

Figure 4: Comparison of the two cars on the base of their specific parameters. 
For the two impact categories, the urban driving impact is higher than the extra-urban driving. However for short driven distances the difference between the two contexts tends to be smaller because of the increasing contribution of the production phase regarding the overall environmental impact.

\section{Conclusions}

Compared to a classic LCA, the range-based modeling LCA allows improving the reliability and the accuracy of an LCA results by taking into account all the possible situations and their influences on each other thanks to the use of a range of values for each parameter of the model instead of an average value. Integration of sensitivity analysis tool with some specific statistical tools and a range-based lifetime driven distance definition enable modeling a complete passenger vehicle fleet on a national level. Thanks to this system, decision makers are supplied with the detailed environmental information per vehicle category and vehicle technology instead of an average national vehicle, which is up most of importance for policy development.

The results of this study show that the life cycle environmental impact of a diesel Sport Utility Vehicle (e.g. the Volkswagen Touareg) is always higher than the one of a petrol small family car (e.g. the Volkswagen Golf) for the two considered impact categories. For the both two cars, the use phase is responsible of more than $88 \%$ of the impact. These conclusions might lightly be change if the end-of-life was taken into account but the trend will be the same. More interesting figures and conclusions could be obtained with a wider range of fuel consumption values during the use phase.

The sensitivity analysis confirms the importance of splitting up the use phase into urban and extra-urban especially for long lifetime driven distances and the relative contribution of the production phase to the overall impact according to the lifetime driven distance. In the further step of this project the alternative vehicles will be assessed and the en-of-life will be included in the model.

\section{References}

[1] ISO, Environmental management-Life cycle assessment-Principles and framework. International Standard ISO 14040, 1997

[2] De Vos, M., De Caevel, B., RangeLCA: principles and methodology; internal document; 2007

[3] De Vos, M., De Caevel, B., RangeLCA training, internal document, 2007

[4] FEBELAUTO, yearly public report, 2006

[5] Spielman, M., Kagi, T., Stadler, P., Tietje, O., Life Cycle Inventories of Transport Services, ecoinvent Reports, ecoinvent data v1.3, 2006

[6] Timmermans, J-M. et al, Environmental rating of vehicles with different fuels and drive trains: a univocal and applicable methodology, European journal of transport and infrastructure research, 6(4), pp. 313-334, 2006

[7] www.ecoscore.be, visited on November 2007 